\title{
Influence of gender and estrous cycle in the forced swim test in rats
}

\author{
Amauri Gouveia Jr. ${ }^{1}$, Taciana Lucas Afonseca ${ }^{2}$, Caio Maximino ${ }^{1}$, Roberto Dominguez ${ }^{3}$ \\ and Silvio Morato ${ }^{4}$ \\ 1 Universidade Federal do Pará, Brazil \\ 2 Universidade Estadual Paulista "Julio de Mesquita Filho", Brazil \\ 3 Universidad Nacional Autónoma de México, Mexico \\ 4 Universidade de São Paulo, Brazil
}

\begin{abstract}
The present work aimed at studying the influence of the estrous cycle in the forced swim test, an animal model of depression. For this, 44 male and female Wistar rats were divided into five groups according to the hormonal state in the first day of the study: metaestrus $(\mathrm{N}=12)$, diestrus $(\mathrm{N}=8)$, proestrus $(\mathrm{N}=7)$, estrous $(\mathrm{N}=6)$ and males $(\mathrm{N}=11)$. They were housed in groups of five, with water and food ad libitum under a 12/12 h light/dark cycle. Females were screened daily for the estrous cycle. The animals were subjected to two swimming sessions in a glass cylinder with water up to $15 \mathrm{~cm}$ at $28 \pm 2^{\circ} \mathrm{C}$. The data of the first five minutes of a 15-min first session were compared to those of a 5-min second session $24 \mathrm{~h}$ later. The results indicate that the latency to the first immobility was substantially reduced in the second session and was longer for females in diestrus and proestrus in the first session. The results also indicate that females in diestrus and proestrus exhibited less immobility than males in the first session; females in diestrus also exhibited less immobility than females in metaestrus. Females in metaestrus and diestrus, as well as males, did not present the decrease in total immobility times in the second session. The present results are analyzed in terms of differential effects of progesterone and estrogen on a learning component and an affective component. Keywords: Forced swim test, estrous cycle, sex differences.
\end{abstract}

Received 5 September 2008; received in revised form 7 November 2008; accepted 10 November 2008. Available online 22 December 2008

\section{Introduction}

Studies on the influences of sex differences on behavior are scarce and, in general, present contradictory and disperse data. The modulation of female behavioral states by sex hormones (in rodents, the estrous cycle) has only recently been properly approached. This is an important matter for pharmacology and human medicine, since many drugs have their effects altered by gender and hormonal condition. Besides, many psychiatric disorders are gender-dependent,

Amauri Gouveia Jr. And Caio Maximino-Universidade Federal do Pará, Departamento de Fisiologia, Centro de Ciências Biológicas. Taciana Lucas Afosenca - Universidade Estadual Paulista "Julio de Mesquita Filho", Bauru-SP, Brazil. Roberto Dominguez Faculdad de Medicina, Universidad Nacional Autónoma de México. Sílvio Morato - Faculdade de Filosofia, Ciencias e Letras da Universidade de São Paulo de Ribeirao Preto. Corresponding regarding this article should be sent to: Amauri Gouveia Jr. And Caio Maximino - Universidade Federal do Pará, Departamento de Fisiologia, Centro de Ciências Biológicas. Campus Guamá, Belém, Pará, Brazil, 66080-180. E-mail: agjunior@ufpa.br such as the increased occurrence of depression and anxiety in women (Holden, 2005). Also, Klink, Robichaud and Debonnel (2002) present data on natural differences between males and females in 5-HT activity, with males exhibiting more active neurons in raphe nuclei.

Studies on the behavioral effects of the menstrual cycle in humans and estrous cycle in rodents investigate a variety of reproductive (Carter, 1993; McCarthy \& Becker, 1993) and non-reproductive behaviors which influence cognitive abilities (Kimura, 1992; Dreher et al., 2006), exploratory and motor activity (Kennet et al., 1986; Curzon, Haaren \& Kennett, 1990; Alonso et al., 1991; Blanchard et al., 1993; Morgan, Schulking \& Pfaff, 2004), defense reaction and defensive attack (Blanchard et al., 1980; Morgan et al., 2004), as well as learned helplessness (Gouveia Jr., 2001). Few studies report on the relations between the estrous cycle and behavioral tests like the elevated plus-maze (Gouveia Jr. \& Morato, 2002), learned helplessness (Jenkins et al., 2000) and elevated T-maze (Gouveia Jr. et al., 2004).

The forced swim test(FST), also known as behavioral despair (Porsolt et al., 1977, 1978), is considered an 
animal model of depression and is mainly used in the screening of antidepressant drugs (Sánchez \& Meier, 1997; Petit-Demouliere, Chenu \& Bourin, 2005). It is usually carried out by exposing an animal to two forced swimming sessions $24 \mathrm{~h}$ apart in a cylinder with water. In the first session, a rat is submitted to the inescapable forced swimming and, after an initial period of vigorous activity, the animal adopts the typical posture of immobility. This stressful situation is repeated the next day and the immobile posture occurs earlier. Measures of the onset and duration of immobility or floating are a score of "depressive-like" behaviors, which are decreased by antidepressant drugs and by other methods to treat depression (Porsolt et al., 1977, 1978). There is some evidence demonstrating that both variables are dissociable in terms of what they index; while the total duration of immobility is taken as a score of affective effects, the latency for the first episode of immobility is taken as a score of contextual/emotional learning and memory effects (West, 1990).

The FST produces an acute release of ACTH and corticosterone by the hypothalamus. In addition, FST procedures increase serotonin release in the hippocampus - an effect that is probably mediated by the activation of corticotropin-releasing hormone activity (Linhorst et al., 2002) - and raise extracellular concentrations of 5-HT in the rat striatum, while diminishing 5-HT levels in the amygdala and lateral septum. At the present moment, it is not possible to determine which of those effects are due to chronic stress and which are due to acute stress. However, the role of serotonin in mediating depression, anxiety and stress has long been acknowledged (Graeff et al., 1996). Deakin and Graeff (1991) suggested that the dorsal raphe-amygdala and dorsal raphe-frontal cortex serotoninergic pathways facilitate conditioned fear, while the DRN-periventricular pathway inhibits innate fight/flight/freeze reactions. The medial raphe nucleus innervation of the dorsal hippocampus seems to mediate resistance to chronic, unavoidable stress (Graeff et al., 1996). Nonetheless, 5-HT1A receptor binding and 5-HT1A mRNA expression were not observed in any hippocampal region after exposure to the FST (López et al., 1998). The FST also stimulates the expression and release of oxytocin and vasopressin in the hypothalamus (Wotjak et al., 1998, 2001). There are a few sex differences in the neurophysiological and neurochemical effects of the FST. Forced swimming induces a reduction in serotoninergic activity in the hippocampus and hypothalamus of female rats, but increases 5-HT activity in those same structures in male rats. 5-HT1A mRNA levels in females' hypothalamus also decrease, while 5-HT1A mRNA levels in the hippocampus increase in male rats (Drossopoulou et al., 2004).

Proestrus present less immobility than males in the first session. This report, however, used a square container for the water, which may have modified the behavior. Another example is the paper by Marvan,
Chavez-Chavez and Santana (1996), using repeated testing of females (no males were tested) and reporting that, with repetition, an increase in immobility occurs during diestrus as compared to estrus.

Using another two-session model of depression, learned helplessness, Jenkins et al. (2000) compared females in estrus and diestrus, males and ovariectomized females previously treated with either progesterone or $\beta$-estradiol. In the first day, rats were subjected to inescapable tail shocks; in the second, to an escape test in the shuttle box. Results showed more learned helplessness (as measured by longer latencies to escape shocks) by females in diestrus than in estrus. In ovariectomized females, progesterone increased escape latencies while $\beta$-estradiol decreased them, indicating the influence of the estrous cycle and the importance of ovarian sex hormones.

The effects of ovarian sex hormones in ovariectomized rats points out a correlation between treatment with sex hormones and the amount of immobility in the FST (Stoffel \& Craft, 2004). In another study with the same test, the administration of estrogen caused immobility to decreased immobility in addition to altering the fos-like immunoreactivity in the anterior cingulate, lateral orbital, retrosplenial, forelimb, parietal and temporal cortices, as well as tenia tecta, anterior claustrum, endopiriform nucleus, anterior and posterior dorsomedial striatum, the shell of the nucleus accumbens, bed nucleus of the stria terminalis, basolateral and medial anterodorsal amygdaloid nuclei, hippocampal CA1 and CA3, centromedial, paraventricular and rhomboid thalamic nuclei, and paraventricular, lateral, ventromedial and dorsomedial hypothalamic nuclei of ovariectomized female rats (Rachman et al., 1998).

The aim of the present study was to investigate the influences of the estrous cycle of rodents on the immobility measures of the behavioral despair test as compared to that of males.

\section{Methods}

\section{Subjects}

Wistar-derived male and female rats $( \pm 200 \mathrm{~g})$ were obtained from the animal housing of the Universidade Estadual Paulista at Botucatu. The females had their estrous cycle monitored by vaginal smears for 14 days. The vaginal smears were obtained by delicately introducing a blastus with saline solution into the vagina, smearing it on laminulae and then inspecting it in an optical microscope. The females were divided into five groups tested according to their hormonal state in the first day of testing: metaestrus $(\mathrm{N}=12)$, diestrus $(\mathrm{N}=8)$, proestrus $(\mathrm{N}=7)$, and estrus $(\mathrm{N}=6)$. Females with irregular estrous cycle were discarded. At the same time, eleven males were tested; male subjects were handled in a similar fashion as females. All animals were housed in groups of 5-6 in the same room, with free water and food under a 12/12 h light/dark cycle (lights on at 7:00 a.m.) with environmental temperature kept between 24 and $27^{\circ} \mathrm{C}$. All tests were carried out between 08:30 and 11:00 a.m. 


\section{Apparatus}

The tests were carried out using a $40 \mathrm{~cm}$ high transparent glass cylinder $16 \mathrm{~cm}$ in diameter, filled up to $15 \mathrm{~cm}$ with water at $28 \pm 2^{\circ} \mathrm{C}$. The sessions were recorded with a video camera (Panasonic RZ315, Brazil) and the behavioral data were later recorded with the Etholog 2.2, a software for recording behavior (Ottoni, 2000). In the present paper, we used Porsolt's definition of immobility (Porsolt et al., 1977, 1978), as the animal floating in the water and making only those movements necessary to keep the head above the surface.

\section{Procedure}

The animals were studied in two sessions that begun with the rat being gently placed into the water in the cylinder. The first session lasted 15 min while, the second lasted 5 min (Porsolt et al., 1977, 1978). Number of fecal boluses, latency for the first immobility episode and total immobility (floating) time were the parameters recorded, and comparisons were made between the first 5 minutes of the first $15 \mathrm{~min}$ session and the total $5 \mathrm{~min}$ of the second session.

\section{Statistical analysis}

One-way ANOVAs (followed, whenever appropriate, by Duncan's test to compare group means) were used to detect effects of the estrous cycle on the first 5 minutes of the first $15 \mathrm{~min}$ session and the total $5 \mathrm{~min}$ of the second session. In addition, Student's $t$-test was used to compare males with females. In all cases, $\mathrm{P}<.05$ was used.

\section{Results}

There were no general differences between males and females in the latency to the first immobility in the first $(t[42]=1.919, \mathrm{P}=.062)$ and second sessions $(t[42]$ $=.421, \mathrm{P}=.676)$. Figure 1 shows the latency to the first immobility episode in the first and second sessions by male and female rats (Panel A: Sex differences in latency for first immobility episode; Panel B: Estrous cycle effects on latency for first immobility; Panel C: Difference in latency for first immobility between training and test). There was a main effect of estrous cycle on the latency to immobility in the first session $(\mathrm{F}[4,39]=5.226, \mathrm{P}=.002)$, but not in the second one $(\mathrm{F}[4,39]=.139, \mathrm{P}=.967)$. The post hoc test indicated that, in the first session, females in diestrus and proestrus took longer to enter immobility than males and females in metaestrus $(\mathrm{P}=.002)$. The $t$ tests comparing the first and second sessions indicated significant decreases in the latency to the first immobility for males $(t[20]=2.457, \mathrm{P}=.023)$ and females in diestrus $(t[14]=4.319, \mathrm{P}<.001)$, proestrus $(t[12]=4.370$, $\mathrm{P}<.001)$ and estrus $(t[10]=3.472, \mathrm{P}=.006)$, but not metaestrus $(t[22]=1.310, \mathrm{P}=.204)$.

Figure 2 shows the total amount of immobility in the first $5 \mathrm{~min}$ of the first and the second sessions by males and females (Panel A: Sex differences in total amount of

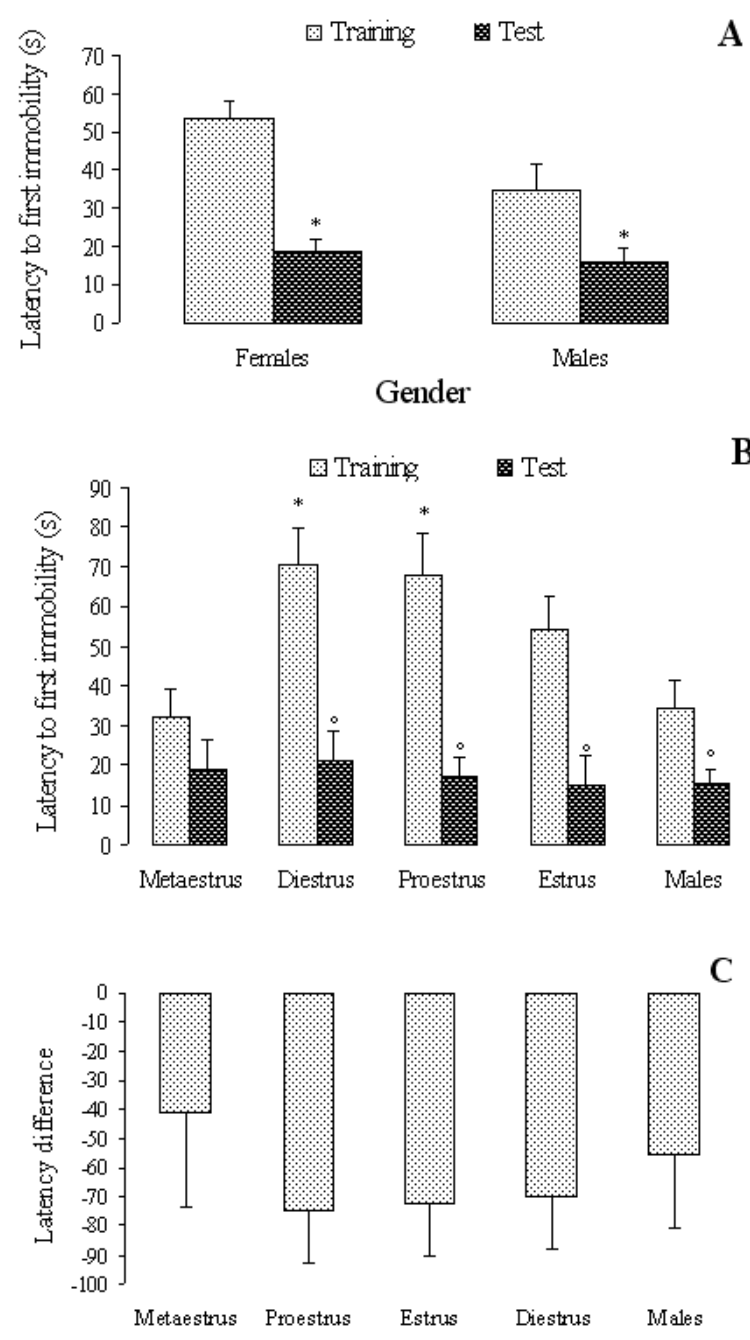

Figure 1. Latency of the first immobility period (s, means) by males and females in different phases of the estrous cycle. Panel A: Sex differences in latency for first immobility episode; Panel B: Estrous cycle effects on latency for first immobility; Panel C: Difference in latency for first immobility between training and test.*, Different from males and metaestrous (Duncan, $\mathrm{p}<.05$ ); ${ }^{\circ}$, Different from training (Student $t$ test, $\mathrm{p}<.05$ ).

immobility; Panel B: Estrous cycle effects on total amount of immobility; Panel C: Difference in total immobility time between training and test). Main effects were observed in the first session $(\mathrm{F}[4,39]=4.605, \mathrm{P}=.004)$, but not in the second one $(\mathrm{F}[4,39]=1.023, \mathrm{P}=.408)$. The post hoc test indicated that, in the first session, females in diestrus presented less total immobility than males and females in metaestrus $(\mathrm{P}=.004)$. It also showed that females in proestrus and diestrus presented less total immobility time than males $(\mathrm{P}=.004)$. The $t$ tests comparing the first and second sessions indicated significant increases in the total immobility time by females in diestrus $(t[14]=3.383, \mathrm{P}=.004)$ and proestrus $(t[12]=-3.343, \mathrm{P}=.006)$, and no differences by males $(t[20]$ $=-.726, \mathrm{P}=.477)$ or females in estrus $(t[10]=-2.170, \mathrm{P}=$ $.055)$ and metaestrus $(t[22]=-.899, \mathrm{P}=.379)$.

A main effect in the number of fecal boluses was also 

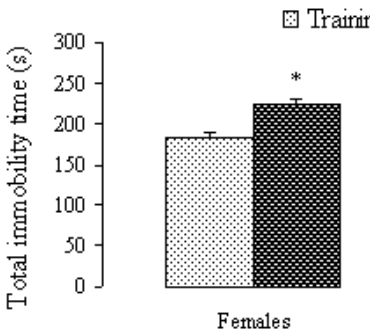

Test

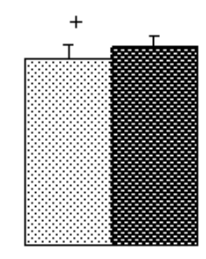

Gender
A

B
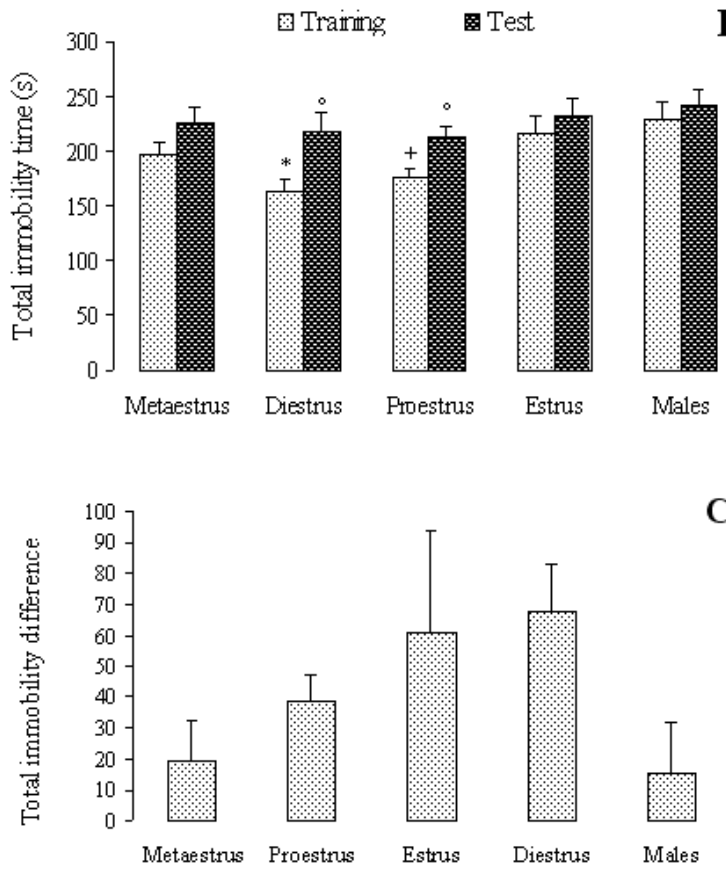

$\mathrm{C}$

Figure 2. Total immobility time (s, mean) by males and females in different phases of the estrous cycle. Panel A: Sex differences in total ammount of immobility; Panel B: Estrous cycle effects on total ammount of immobility; Panel C: Difference in total immobility time between training and test.*, Different from males and metaestrous; ${ }^{+}$, different from males (Duncan post-hoc test, $\mathrm{p}<.05$ ). ${ }^{\circ}$, Different from training (Student's t test, $\mathrm{p}<.05$ ).

observed, with differences between males and females in the first session $(\mathrm{t}[42]=2.865, \mathrm{P}=.006)$, as well as between males and females in proestrus in the first session ( $\mathrm{F}[4,39]$ $=2.66, \mathrm{P}=.047$ ). A statistically significant effect was also observed between the first and second sessions in proestrus females $(t[12]=2.444, P=.031)$. Figure 3 summarizes data for fecal boluses (Panel A: Sex differences in number of fecal boluses; Panel B: Estrous cycle effects on number of fecal boluses; Panel C: Difference in number of fecal boluses between training and test).

\section{Discussion}

The present data indicates that the estrous cycle influenced both parameters of immobility: the increases in the latency of the first immobility and the decreases in total immobility time by females in diestrus and proestrus. The effects of the estrous cycle on the number of fecal boluses, observed mainly in the first session, are conceivably indexical of a smaller threshold for stress in female rats, especially when in proestrus. The present results replicate the increase in the latency for the first immobility in diestrus and proestrus and the decrease in total immobility time in the first session by females in diestrus reported by Barros and Ferigolo (1998) and Marvan et al. (1996). In addition, they support data also obtained in two sessions with learned helplessness, another animal model of depression (Jenkins et al., 2000).

The present results support previous reports on the behavioral effects of the estrous cycle in other animal models. Diestrus has different effects in different models. In the elevated plus-maze, it causes increases in the open arm exploration (Diaz-Veliz et al., 1989, 1997; Gouveia Jr. \& Morato, 2002); in the two-way avoidance task, it enhances acquisition (Diaz-Veliz et al., 1989); it increases long term food ingestion (Laviano et al., 1996) and improves palatability reactivity (Claker \& Ossenkopp, 1998); and finally, in the elevated T-maze, it increases the first avoidance latency, or baseline (Gouveia Jr. et al., 2004).

Our data, however, failed to replicate the wellknown increase in the amount of immobility observed between the first and the second sessions in males (e.g. Porsolt et al., 1977, 1978). The absence of this effect is possibly due to the small dimensions of our apparatus and to the height of the water column. Our apparatus, although very similar in dimensions to the one used by Porsolt et al. $(1977,1978)$ in their original papers, is smaller than those used by other authors in some more recent papers (Molina-Hernandez \& Tellez-Alcantara, 2001; Cryan, Marlou \& Lucki, 2002; Drossopoulou et al., 2004). In these studies, the investigators used larger cylinders and reported less immobility in the first session and larger increases in the second one.

The differences in total immobility in the training session between males and females in diestrus are conceivably generated by the action of progesterone. In general, there are peaks of progesterone secretion in two phases of the cycle, diestrus and estrus, but in diestrus it is secreted together with estradiol (Schwartz, 1969). Changes in progesterone metabolites in the hippocampus were observed in female rats in proestrus, modulating immobility in the FST (Frye \& Walf, 2002). It is possible that the concomitant presence of both estradiol and progesterone tends to mutually cancel each other's effects on behavior (Bethea et al., 1999). Data in the elevated plus-maze support this hypothesis (Gouveia Jr. \& Morato, 2002). Support also comes from other animal models, such as two-way avoidance (Beatty \& Beatty, 1970), open-field (Blizand et al., 1975) and conditioned avoidance (Diaz-Veliz et al., 1989). In all these studies, several behavioral measures remained unchanged when the authors administered both hormones (each of which produces effects when given in isolation) simultaneously. 
Estrogen modulates the firing activity of dorsal raphe nucleus 5-HT neurons in female rats (Robichaud \& Debonnel, 2005), and induces changes in 5-HT1A binding and G-protein activation (Österlund, Halldin \& Hurd, 2000; LeSaux \& Di Paolo, 2005). A lightcycle-dependent effect on extracellular serotonin concentrations in the mediobasal hypothalamus was observed in females in diestrus and proestrus (Maswood et al., 1999). CA1 firing in response to Schaffer colateral stimulation was also greater in estrus and proestrus, while CA3 responses due to repetitive hilar stimulation evoked multiple population spiking in estrus and proestrus (Scharfman et al., 2003). Supposedly, those alterations, as well as changes in synaptic density, are a function of estrogenic activity in the median raphe nucleus (Prange-Kiel, Rune \& Leranth, 2004). As such, the behavioral effects observed during proestrus could be correlated with the estrogen-progesterone equilibrium and its effects on the serotoninergic activity of the dorsal and median raphe nuclei, which, in turn, alters hypothalamic and hippocampal activity.

Progesterone effects are probably mediated by GABA, 5-HT1A and 5-HT2A receptors (Kaura et al, 2007); the GABA receptor is modulated by steroid hormones which can alter motor responses, on the one hand, and behaviors related to mood and anxiety, on the other (Biltran \& Dowd, 1996; Concas et al., 1999; Fink et al., 1999). Studies have shown that, during estrus, 5-HT exhibits changes in synthesis, release, reuptake and catabolism (Biegon, Bercovitz \& Samuel, 1980; Uphouse et al., 1986; Gundlah, Simon \& Auerbach, 1998), and fluctuations in this indolamine are correlated with the action of estrogen and progesterone (Kueng, Wirz-Justice \& Chappuis-Arndt, 1976; Di Paolo et al., 1983; Renner, Krey \& Luine, 1987; Gereau, Kedzie \& Renner, 1993; Famer et al., 1996). Some authors report variations in 5-HT extracellular concentrations in diestrus, the higher concentrations being found in the hypothalamus (Gundlah et al., 1998; Maswood et al., 1999).

Some reports have shown that progesterone may modulate the $\mathrm{GABA}_{\mathrm{A}}$ receptor function by potentiating it (Lambert et al., 2003; Lambert \& Belelli, 2005; Kaura et al., in press) while inhibiting the activity of 5-HT neurons (Kaura et al., in press). Other studies on lordosis behavior reported that the activation of 5-HT1A and 5-HT2 receptors present opposite effects: 5-HT1A activation inhibits lordosis while 5-HT2 activation facilitates it (Wolf, Calderola-Patuszka \& Uphouse, 1998; Uphouse et al., 2003). Stressing rats also causes lordosis to decrease, similar to the 5-HT1A receptor activation effects (Uphouse et al., 2003). In addition, 5-HT2A activation causes an antidepressant effect, but only in the presence of estrogen (Rybaczyk et al., 2005).

One shortcoming of the methodology used in this experiment is that estrous cycle stages were not analysed in the second session. Given that the FST seems to alter hypothalamic activity (Wotjak et al., 1998, 2001), it is possible that the stage of the estrous cycle in the second session was altered by the increase in estrogen (Shors et al., 1999); as such, our results would be more difficult to analyze, restraining our hypotheses to the observable effects on behavior. However, the observation that estrous cycle stages mediated emotional elements of the FST, but not its memory elements, is consistent with data found elsewhere (Palanza, 2001).

Based on the above discussion, a hypothesis can be made that the behavioral effects observed in the present experiment may be due to the combined effects of (1) a decrease in extracellular serotonin, (2) a decrease in 5-HT2 activity, (3) an increase in 5-HT1A activity, as well as (4) an increase in $\mathrm{GABA}_{\mathrm{A}}$ receptor activation. These effects are caused by changes in circulating levels of estrogen and free progesterone (a decrease in the first and an increase in the latter). The effect observed on
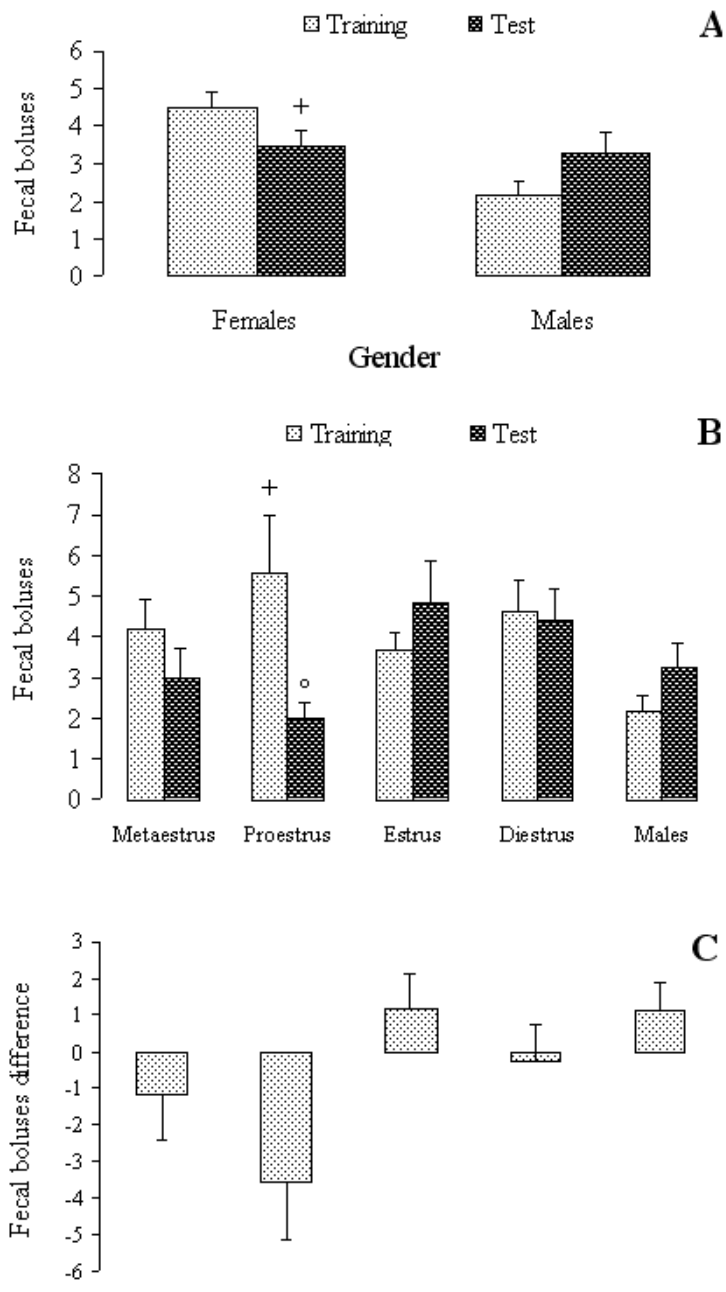

Figure 3. Number of fecal boluses (n, mean) by males and females in different phases of the estrous cycle. Panel A: Sex differences in number of fecal boluses; Panel B: Estrous cycle effects on number of fecal boluses; Panel C: Difference in number of fecal boluses between training and test. + , Different from females (Student's t test, $\mathrm{P}<.05$ ); ++ , different from proestrus (Duncan post-hoc test, $\mathrm{p}<.05$ ). *, Different from training (Student's t test, $\mathrm{p}<.05$ ). 
total immobility, but not on latencies for immobility in the second session, could be due to a differential effect of both hormones on systems that mediate learning and emotionality in the forced swim test (Shors \& Leuner, 2003). One alternative hypothesis, arisen from the data of the present experiment, contrasted with evidence in the literature, is that the acute swim stress raised estrogen levels in the brain, either directly (Shors et al., 1999) or indirectly, via augmentation of oxytocin and/or arginine-vasopressin levels (Wotjak et al., 1998, 2001). However, more experiments are needed in order to further confirm and refine those hypotheses.

\section{Acknowledgments}

S. M. was the recipient of a research fellowship from CNPq (351317/96-1).

\section{References}

Alonso, S.J., Castellano, M.A., Afonso, D., \& Rodriguez, M. (1991). Relationship between behavioral despair and open-field activity. Physiology and Behaviour, 49, 69-72.

Barros, H.T.M., \& Ferigolo, M., (1998). Ethopharmacology of imipramine in the forced-swimming test: Gender differences. Neuroscience and Biobehavioral Reviews, 23, 279-286.

Beatty, W.W., \& Beatty, P.A (1970). Hormonal determinants of sex differences in avoidance behavior and reactivity to electrical shocks in the rat. Journal of Comparative and Physiological Psychology, 73, 446-445.

Bethea, C.L., Pecins-Thompson, M., Schutzer, W.E., Grundlah, C., \& Lu, Z.N. (1999). Ovarian steroids and serotonin neural function. Molecular Neurobiology, 18, 87-123.

Biegon, A., Bercovitz, H., \& Samuel, D. (1980). Serotonin receptor concentration during the estrous cycle of the rat. Brain Research, 187, 221- 225.

Biltran, D., \& Dowd, J.A. (1996). Ovarian steroids modify the behavioral and neurochemical response of the central benzodiazepine receptor. Psychopharmacology (Berl.), 125, 65-63.

Blanchard, R.J., Kleinschmidt, C.F., Fukunaga-Stinson, C., \& Blanchard, D.C. (1980). Defensive attack behavior in male and female rats. Animal Learning and Behavior, 8, 177-183.

Blanchard, R.J., Yudko, E.B., Rodgers, R.J., \& Blanchard, C.D. (1993). Defense system psychopharmacology: An ethological approach to the pharmacology of fear and anxiety. Behavioural Brain Research, 58, 155-165.

Blizand, D.A., Lippman, H.R., \& Chen, J.J (1975). Sex differences in open-field behavior in the rat: The inductive and activactional role of gonadal hormones. Physiology and Behavior, 14, 601-608.

Carter, C.S. (1993). Hormonal influences of human sexual behavior. In: Becker, J.B., Breedlove, S.M., \& Crews, D. (Eds.) Behavioral Endocrinology. (pp. 205-222). Cambridge: MIT Press.

Claker, S.N.D.A., \& Ossenkopp, K.P. (1998). Taste reactivity response in rats: Influences of sex and the estrous cycle. American Journal of Physiology, 274, R718-R724.

Concas, A., Follesa, P., Barbaccia, M.L., Pursy, R.H., \& Biggio, G. (1999). Physiological modulation of GABAA receptor plasticity by progesterone metabolites. European Journal of Pharmacology, 375, 225-235.

Cryan. J.F., Marlou, A., \& Lucki, I. (2002). Assessing antidepressant activity in rodents: Recent developments and futures needs. Trends in Pharmacological Sciences, 23, 238-245.

Curzon, G., Haaren, D.J., \& Kennett, G.A. (1990). Sex differences in animal model of depression. In: Leonard, B., \& Spencer C. (Eds.).Antidepressants: Thirty Years On. (pp. 101-108). London: CNS Publications.

Deakin, J.F.W., \& Graeff, F.G. (1991). 5-HT and mechanisms of defence. Journal of Psychopharmacology, 5, 305-315.

Di Paolo, T., Daigle, M., Picard, V. \& Barden, N. (1983). Effect of acute and chronic $17 \beta$-estradiol treatment on serotonin and 5-hydroxyindole acetic acid content of discrete brain nuclei of ovariectomized rat. Experimental Brain Research, 51, 73-76.

Diaz-Veliz, G., Alarcón, T., Espinoza, C., Dussaubat, N., \& Mora, S. (1997). Ketaserin and anxiety levels: Influences of gender, estrous cycle, ovariectomy and ovarian hormones in female rats. Pharmacology, Biochemistry and Behavior, 58, 637-642.

Diaz-Veliz, G., Soto, V., Dussaubat, N., \& Mora, S. (1989). Influences of the estrous cycle, ovariectomy and estradiol replacement upon the acquisition of conditioned avoidance responses in rats. Physiology and Behavior, 46, 397-401.

Dreher, J.-C., Schmidt, P.J., Kohn, P., Furman, D., Rubinow, D. \& Berman, K. F. (2006). Menstrual cycle phase modulates rewardrelated neural function in women. Proceedings of the National Academy of Sciences USA, 104, 2465-2470.

Drossopoulou, G., Antoniu, K., Kitrani, E., Papathanasiou, G., Papalexi, E., Dalla, C., \& Papapoulou-Daifoti, Z. (2004). Sex differences in behavioral, neurochemical and neuroendocrine effects induced by the forced swim test in rats. Neuroscience, $126,849-857$

Famer, C.J., Isakson, T.R., Coy, D.J., \& Renner, K..J (1996). In vivo evidence for progesterone dependent decreases in serotonin release in the hypothalamus and midbrain central grey: Relation to the induction of lordosis. Brain Research, 711, 84-102.

Fink, G., Sumner, B., Rosie, R., Wilson, H., \& McQueen, J. (1999) Androgen actions on central serotonin neurotransmission: Relevance for mood, mental state and memory. Behavioural Brain Research, 105, 53-68.

Frye, C.A., \& Walf, A.A. (2002). Changes in progesterone metabolites in the hippocampus can modulate open field and forced swim test behavior of proestrous rats. Hormones and Behavior, 41, 306-315.

Gereau, R.W., Kedzie, K.A., \& Renner, K.J. (1993). Effects of progesterone on serotonin turnover in rats primed with estrogens implants into ventromedial hypothalamus. Brain Research Bulletin, 32, 293-300.

Gouveia Jr., A. (2001). Efeitos da administração aguda de imipramina sobre o desamparo aprendido de ratos machos e fêmeas. Acta Comportamentalia, 9, 19-30.

Gouveia Jr., A., \& Morato, S (2002). Influência do ciclo estral sobre o desempenho de ratos no labirinto em cruz elevado. Interação em Psicologia, 6, 141-148.

Gouveia Jr., A., Santos, U.D., Felisbino, F., Afonseca, T.L., Antunes, G., \& Morato, S. (2004). Influence of the estrous cycle on the behavior of rats in the elevated T-maze. Behavioural Processes, $67,167-171$.

Graeff, F.G., Guimarães, F.S., de Andrade, T.G.C.S., \& Deakin, J.F.W. (1996). Role of 5-HT in stress, anxiety and depression. Pharmacology, Biochemistry and Behavior, 54, 129-141.

Gundlah C., Simon, L.S., \& Auerbach, S.B. (1998). Differences in hypothalaminc serotonin between estrous phases and gender: An in vivo microdialysis study. Brain Research, 785, 91-96.

Holden, C. (2005). Sex and the suffering brain. Science, 308, 1574-1577.

Jenkins, J.A., Williams, P., Kramer, G.L., Davis, L.L., \& Petty, F. (2000). The influence of gender and the estrous cycle on learned helplessness in the rat. Biological Psychiatry, 58, 147-158.

Kaura, V., Ingram, C. D., Gartside, S. E., Young, A. H., \& Judge, S. J. (2007). The progesterone metabolite allopregnanolone potentiates GABA receptor-mediated inhibition by 5 -HT neuronal activity. European Neuropsychopharmachology, 17, 108-115Kennett, G.A., Chaouloff, F., Marcou, M., \& Curzon, G. (1986).

Females are more vulnerable than males in an animal model of depression - The possible role of serotonin. Brain Research, $382,416-421$

Kimura, D. (1992). Sex differences in the brain. Scientific American, $267,119-125$

Klink, R., Robichaud, M., \& Debonnel, G. (2002). Gender and gonadal status modulation of dorsal raphe nucleus serotonergic neurons. Part I: Effects of gender and pregnancy. Neuropharmacology, 43, $1119-1128$

Kueng, W., Wirz-Justice, A., \& Chappuis-Arndt, E. (1976). Regional brain variations of tryptophan, monoamines, monoamine oxidase activity, plasma free and total tryptophan during the estrous cycle of the rat. Neuroendocrinology, 21, 289-96.

Lambert, J.J., Belelli, D., Peden, D.R., Vardy, A.W., \& Peters, J.A. 
(2003). Neurosteroid modulation of GABAA receptors. Progress in Neurobiology, 71, 67-80.

Lambert, J.J., \& Belelli, D. (2005). Neurosteroids: Endogenous regulators of the GABAA receptor. Nature Reviews Neuroscience, $6,565-575$.

Laviano, A., Meguido, M.M., Yang, Z., \& Renvyle, T. (1996). Comparison of long-term feeding pattern between male and female Fisher 344 rats: Influences of the estrous cycle. American Journal of Psychiatry, 270, 413-419.

LeSaux, M., \& Di Paolo, T. (2005). Changes in 5-HT1A receptor binding and G-protein activation in the rat brain after estrogen treatment: Comparison with tamoxifen and raloxifene. Rev. Psychiatr. Neurosci., 30, 110-117.

Linthorst, A.C.E., Peñalva, R.G., Flachskamm, C., Holsboer, F., \& Reul, J.M.H.M. (2002). Forced swim stress activates rat hippocampal serotoninergic neurotransmission involving a corticotropin-releasing hormone receptor-dependent mechanism. European Journal of Neuroscience, 16, 2441-2452.

López, J.F., Chalmers, D.T., Little, K.Y., \& Watson, S.J. (1998). Regulation of serotonin 1A, glucocorticoid, and mineralocorticoid receptor in rat and human hippocampus: Implications for the neurobiology of depression. Biological Psychiatry, 43, 547-573.

Marvan, M.L., Chavez-Chavez, L., \& Santana, S. (1996). Clomipramine modifies fluctuations of forced swim test immobility in different phases of the rat estrous cycle. Archives of Medical Research, 27, 83-86.

Maswood, S., Truitt, W., Hotema, M., Caldarola-Pastuszka, M., \& Uphouse, L. (1999). Estrous cycle modulation of extracellular serotonin in mediobasal hypothalamus: Role of serotonin transporter and terminal autoreceptors. Brain Research, 831, 146-154.

McCarthy, M.M., \& Becker, J.B. (1993). Neuroendocrinology of sexual behavior in the female. In: Becker, J.B., Breedlove, S.M., \& Crews, D. (Eds.). Behavioral Endocrinology. (pp. 117-152). Cambridge, MA: MIT Press.

Molina-Hernandez, M., \& Tellez-Alcantara, N.P. (2001). Antidepressantlike actions of pregnancy, and progesterone in Wistar rats forced to swim. Psychoneuroendocrinology, 26, 479-91.

Morgan, M.A., Schulking, J., \& Pfaff, D.W. (2004). Estrogens and nonreproductive behaviors related to activity and fear. Neuroscience and Biobehavioral Reviews, 28, 55-63.

Österlund, M.K., Halldin, C., \& Hurd, Y.L. (2000). Effects of chronic $17 \beta$-Estradiol treatment on the serotonin 5-HT1A receptor mRNA and binding levels in the rat brain. Synapse, 35, 39-44.

Ottoni, E.B. (2000). Etholog 2.2 - A tool for the transcription and timing of behavior observation sessions. Behavior Research Methods, Instruments, \& Computers 32, 446-449.

Palanza, P. (2001). Animal models of anxiety and depression: How are females different? Neuroscience and Biobehavioral Reviews, $25,219-233$.

Petit-Demouliere, B., Chenu, F., \& Bourin, M. (2005). Forced swimming test in mice: A review of antidepressant activity. Psychopharmacology, 177, 245-255.

Porsolt, R.D., Anton, G., Blavet, N., \& Jalfre, M. (1978). Behavioral despair: A new model sensitive to antidepressant treatments. European Journal of Pharmacology, 47, 379-391.

Porsolt, R.D., Le Pichon, M., \& Jalfre, M. (1977). Depression: A new model sensitive to antidepressants treatment. Nature, 266, 730-732.

Prange-Kiel, J., Rune, G.M., \& Leranth, C. (2004). Median raphe mediates estrogenic effects to the hippocampus in female rats. European Journal of Neuroscience, 19, 309-317.

Rachman, I.M., Unnerstall, J.R., Pfaff, D.W., \& Cohen, R.S. (1998). Estrogen alters behavior and forebrain $\mathrm{C}$-fos expression in ovarectomized rats subjected to the forced swim test. Proceedings of the National Academy of Sciences USA 95, 13941-13946.

Renner, K.J., Krey, L.C., \& Luine, V.N. (1987). Effect of progesterone on monoamine turnover in the brain of the estrogen-primed rat. Brain Research Bulletin, 19,195-202.

Robichaud, M., \& Debonnel, G. (2005). Oestrogen and testosterone modulate the firing activity of dorsal raphe nucleus serotoninergic neurones in both male and female rats. Journal of Endocrinology, 17, 179-185.

Rybaczyk, L.A., Bashaw, M.J., Pathak, D.R., Moody, S.M., Gilders, R.M., \& Holzschu, D.L. (2005). An overlooked connection: Serotoninergic mediation of estrogen-related physiology and pathology. BMC Womens Health, 5, 12-22.

Sánchez, C., \& Meier, E. (1997). Behavioral profiles of SSRIs in animal models of depression, anxiety and aggression. Are they all alike? Psychopharmacology, 129, 197-205.

Scharfman, H.E., Mercurio, T.C., Goodman, J.H., Wilson, M.A., \& MacLusky, N.J. (2003). Hippocampal excitability increases during the estrous cycle in the rat: A potential role for brainderived neurotrophic factor. Journal of Neuroscience, 23, $11641-11652$

Schwartz, N.B. (1969). A model for the regulation of ovulation in the rat. Recent Progresses in Hormone Research, 25, 1-55.

Shors, T.J., \& Leuner, B. (2003). Estrogen-mediated effects on depression and memory formation in females. Journal of Affective Disorders, 74, 85-96.

Shors, T.J., Pickett, J., Wood, G.E., \& Paczynski, M. (1999). Acute stress enhances estrogen levels in the female rat. Stress, 3, 163-171.

Stoffel, E.C., \& Craft, R.M. (2004). Ovarian hormone withdrawalinduced "depression" in female rats. Physiology and Behaviour, $83,505-513$.

Uphouse, L., Willians, L.J.L., Eckols, K.V., \& Sierra, V. (1986). Variations in binding of [3H]5-HT to cortical membranes during the female rat estrous cycle. Brain Research, 381, 376-381.

Uphouse, L., White, S., Harrison, L., Hiegel, C., Majumda, D. Guptarak, J., \& Truitt, W.A. (2003). Restraint accentuates the effects of 5- HT2 receptor antagonist and a 5-HT1A receptor agonist on lordosis behavior. Pharmacology, Biochemistry and Behavior, 76, 63-73.

West, A.P. (1990). Neurobehavioral studies of forced swimming: The role of learning and memory in the forced swim test. Progress in Neuropsychopharmacology and Biological Psychiatry, 14, 863-877.

Wolf, A., Calderola-Patuszka, M., \& Uphouse, L. (1998). Facilitation of female lordosis behavior by hypothalamic infusion of 5-HT2a/2c receptor agonists. Brain Research, 779, 84-95.

Wotjak, C.T., Ganster, J., Kohl, G., Holsboer, F., Landgraf, R., \& Engelmann, M. (1998). Dissociated central and peripheral release of vasopressin, but not oxytocin, in response to repeated swim stress: New insights into the secretory capacities of peptidergic neurons. Neuroscience, 85, 1209-1222.

Wotjak, C.T., Naruo, T., Muraoka, S., Simchen, R., Landgraf, R., \& Engelmann, M. (2001). Forced swimming stimulates the expression of vasopressin and oxytocin in magnocellular neurons of the rat hypothalamic paraventricular nucleus. European Journal of Neuroscience, 13, 2273-2281. 